\title{
Alterations of pulmonary capillary filtration and leukotriene synthesis due to infusion of a lipid emulsion enriched with Omega-3-fatty acids
}

\author{
T KOCH, A HELLER, I BREIL, K VAN ACKERN, H NEUHOF
}

Summary

Objective: This study focuses on the question of whether the pulmonary response to inflammatory stimulation, resulting in increased vascular resistance and permeability, could be attenuated by short-term infusion of triglycerides containing omega (n)-3 fatty acids. The parenteral application of a lipid emulsion prepared from fish oil (Omegavenös®) was tested in comparison with a soy oil preparation (Lipovenös $\left.{ }^{\circledR}\right)$. The hypothesis was that infusion of eicosapentaenoic acid (EPA), the major n-3 fatty acid contained in fish oil, may interfere with eicosanoid synthesis in such a manner that stimulation results in the release of the less vasoconstrictive and permeability enhancing metabolites of EPA instead of those of arachidonic acid (AA).

Design: Isolated lungs from anaesthetised rabbits were ventilated and recirculation-perfused $(200 \mathrm{ml} / \mathrm{min})$ with $250 \mathrm{ml}$ cell-free buffer solution to which either $2.5 \mathrm{ml}$ saline (controls, $n=3), 2.5 \mathrm{ml}$ Lipovenös ${ }^{\circledR} 10 \%(n=11)$, or $2.5 \mathrm{ml}$ Omegavenös ${ }^{\circledR} 10 \%(\mathrm{n}=13)$ were added. To study the alterations of pulmonary vascular permeability in states of inflammatory stimulation, lungs of each group were stimulated with calcium-ionophore A23187 (1 $\mu \mathrm{M})$. The capillary filtration coefficients $\left(\mathrm{C}_{\mathrm{fc}}\right)$, as an index of permeability, were determined before and after administration of A23187 at 30-minute intervals during an observation period of 210 minutes. To study lipid effects on neutrophil-mediated inflammatory reactions, the same protocol was performed in additional experiments in which isolated human polymorphonuclear (PMN) leukocytes $\left(10^{8}\right)$ were added to the perfusion fluid. For analysis of the 5-lipoxygenase mediator profile, perfusate samples were taken at 1-hour intervals.

Department of Anesthesiology and Operative Intensive Care Medicine Klinikum Mannheim, Mannheim ${ }^{1}$ and Division of Clinical Pathophysiology and Experimental Medicine/Department of Internal Medicine, University of Gießen, Gießen, Germany

T Koch, ${ }^{1}$ A Heller, ${ }^{1}$ I Breil, ${ }^{1}$ K van Ackern, ${ }^{1} \mathrm{H}$ Neuhof ${ }^{2}$
Key words:

Eicosanoids Lung

Eicosapentaenoic acid N-3 fatty acids

Fish oil

Vascular permeability

Main results: Baseline values of $\mathrm{C}_{\mathrm{fc}}\left(0.23 \pm 0.01\right.$ g.min ${ }^{-1}$. $\left.\mathrm{mmHg}^{-1} .100 \mathrm{~g}^{-1}\right)$ were comparable in all groups. Calciumionophore challenge induced a several-fold increase in $\mathrm{C}_{\mathrm{fc}}$ which was significantly $(\mathbf{p}<0.05)$ attenuated in the Omegavenös ${ }^{\circledR}$-perfused lungs compared to the Lipovenös ${ }^{\circledR}$ group. The vascular reactions during Omegavenös ${ }^{\circledR}$ perfusion were accompanied by a reduction of tetraen-leukotrienes and a moderate increase in pentaenmetabolites.

Conclusion: The data demonstrate that altering the eicosanoid precursor availability by infusion of $n-3$ fatty acids a protective effect is exerted on the pulmonary vascular reaction to inflammatory stimulation.

\section{Introduction}

Since the epidemiological studies of Bang and Dyerberg, ${ }^{1,2}$ which showed that Eskimos have low rates of coronary heart disease and cancer, growing interest has been focused on the importance of eicosapentaenoic acid (EPA) in the prevention of cardiovascular diseases. These findings, confirmed in subsequent studies in fish-eating populations, ${ }^{3,4}$ point towards the antithrombotic and anti-inflammatory properties of EPA, the major n-3 fatty acid contained in fish oil. In accordance with these observations, dietary supplementation with large amounts of fish oil was described to result in clinical improvement of chronic inflammatory diseases such as ulcerative colitis and psoriasis. ${ }^{5-7}$ The central question 
addressed in the present study is whether short-time infusion of $n-3$ fatty acids might be a putative therapeutic regimen for modulating acute inflammatory reactions, ie increased pulmonary permeability, the major pathophysiological event occurring during the development of ARDS.

The anti-inflammatory effects, observed after long-term administration of dietary n-3 fatty acids in animal and human studies, seem to be due to an augmented generation of EPAderived eicosanoids. ${ }^{8-10}$ Diets supplemented with n-3 fatty acids alter the composition of cell membranes in such a way that n-3 fatty acids partially replace n-6 fatty acids in the membrane of almost all cells, ie erythrocytes, ${ }^{11}$ neutrophils, ${ }^{12}$ platelets, ${ }^{13,14}$ endothelial cells, monocytes and brain and liver cells, ${ }^{15}$ resulting in an enhanced release of products derived from EPA with an attenuated spectrum of biological activity compared to those derived from AA. ${ }^{16-17}$ Furthermore, the formation of platelet activating factor (PAF), which has a wide range of pro-inflammatory properties, is also reduced by EPA through interference with the turnover of the PAF precursor pool. ${ }^{18}$

Interference with eicosanoid synthesis by altering the eicosanoid precursor availability seems to be a feasible mechanism, since eicosanoids are derived from essential fatty acids which must be provided in the diet. ${ }^{19} \mathrm{AA}$ is the major substrate in mammals for the production of biologically active eicosanoids via the cyclooxygenase and lipoxygenase pathways. EPA competes with AA for prostaglandin and leukotriene synthesis on the cyclooxygenase and on the 5lipoxygenase level, thus modulating the production of dieneprostanoids (for example, $\mathrm{PGE}_{2}, \mathrm{PGI}_{2}, \mathrm{TXA}_{2}$ ) and of tetraene-leukotrienes (for example $\mathrm{LTC}_{4}$ ) derived from AA in favour of the corresponding triene-prostanoids (for example $\mathrm{PGE}_{3}, \mathrm{PGI}_{3}, \mathrm{TXA}_{3}$ ) and pentaene-leukotrienes (for example $\mathrm{LTC}_{5}$ ) derived from EPA. ${ }^{19}$ In recent in vitro studies which focused on the kinetics of the incorporation and metabolism of n-3 fatty acids, we demonstrated that n-3 fatty acids were rapidly integrated into the exchange pool of free fatty acids in the lung tissue and were metabolised even after a preceding 3hour lipid infusion. ${ }^{20}$

Considering that eicosanoids play an important role in the pathogenesis of pulmonary oedema following trauma, shock and sepsis, ${ }^{21}$ it should be evaluated whether or not infusion of n-3 fatty acids exerts a protective effect on pulmonary vascular reaction and mediator release due to inflammatory stimulation. For this purpose, the parenteral application of a lipid emulsion prepared from fish oil was compared with a soy oil preparation in a reproducible animal model. From the clinical point of view, the intravenous route may be advantageous in order to combine parenteral nutrition with anti-inflammatory intervention. In addition, slow kinetics and limited availability of dietary fatty acids for effective modulation of inflammatory mediator profiles can thus be surmounted. Calcium-ionophore A23187, a non-specific inflammatory stimulus, was used to simulate an inflammatory response with enhanced eicosanoid synthesis. Calcium-ionophore induces an intracellular calcium influx, thereby activating the enzyme phospholipase $\mathrm{A}_{2}$ which liberates the precursor fatty acids for eicosanoid synthesis from membrane phospholipids. Alterations of pulmonary vascular permeability were monitored by repetitive determinations of the capillary filtration coefficient $\left(\mathrm{C}_{\mathrm{fc}}\right)$ and compared with the observed changes in the leukotriene profile.

\section{Materials and methods}

\section{The lung model}

The techniques of preparing and perfusing isolated rabbit lungs have been previously described in detail. ${ }^{22}$ Standard breed rabbits (ortictolagus caniculus) of either sex weighing $3,100 \pm 196 \mathrm{~g}($ mean $\pm \mathrm{SD})$ were anaesthetised with pentobarbital sodium $60-80 \mathrm{mg} / \mathrm{kg}$ and anticoagulated with heparin-sodium $1000 \mathrm{U} / \mathrm{kg}$ injected in the ear vein. The trachea was cannulated and the rabbits were mechanically ventilated by means of a Starling pump (B Braun, Melsungen, Germany). The thorax was opened via the diaphragm and, after a median sternotomy, catheters were inserted into the pulmonary artery and the left atrium, passing through the aortic and mitral valves. The lung and heart organ preparation was isolated and suspended from a weight transducer (Hottinger, Baldwin Meßtechnik Type $\mathrm{U} 1$, Darmstadt, Germany) in a temperature-controlled $\left(37^{\circ} \mathrm{C}\right)$ and humidified chamber. After the cannulation procedure, the lungs were perfused with $250 \mathrm{ml}$ Krebs Henseleit hydroxyethyl-starch buffer solution (KHHB) by a roller pump (Masterflex ${ }^{\circledR} 7566-10$, Cole Palmer Instruments Co, Chicago, USA) at a constant volume inflow of $200 \mathrm{ml} / \mathrm{min}$ in a recirculating system. The lungs were ventilated with $4 \% \mathrm{CO}_{2}$ in air (frequency $25 / \mathrm{min}$, tidal volume $30 \mathrm{ml}$, PEEP $0.5-1.0$ $\mathrm{cmH}_{2} \mathrm{O}$ ) and, in order to avoid atelectasis formation, intermittently flushed by increasing the expiratory pressure up to $3 \mathrm{cmH}_{2} \mathrm{O}$ for three inspirations. The pulmonary arterial (PAP), venous (PVP) and airway pressures (AP) were continuously recorded via Statham strain gauge transducers. Using two separate perfusion circuits, the perfusion fluid was exchanged for fresh buffer 2 minutes after the beginning of the extracorporeal circulation and again after increasing the flow up to $200 \mathrm{ml} / \mathrm{min}$ (30 minutes).

After another 30-minute steady-state period, these lungs had a constant mean PAP of 7.5-8.5 mmHg (zero-referenced at the hilum); PVP was set at $0 \mathrm{mmHg}$. The only lungs selected for the study were those that showed a homogenous white appearance with no signs of haemostasis or oedema formation, and which were completely isogravimetric during the steady-state period. In pilot experiments, the perfusion with KHHB has been documented to maintain integrity of the microcirculation for more than 5 hours in our model, which was assessed by measurements of PAP and weight gain, by biochemical analysis (LDH, AA-metabolites, histamine) as well as by ultrastructural studies. During the observation period, neither significant alterations in $\mathrm{LDH}$, eicosanoids and histamine release, nor structural abnormalities (for example, destruction of endothelial or epithelial cells) were found.

\section{Measurements}

The PAP, PVP, AP and weight gain (as an indicator of extravascular lung water) as well as the $\mathrm{pH}$ value were continuously recorded (Rikadenki, Kogyo, Tokyo, Japan). 
The oncotic pressure (Onkometer BMT921, Dr Karl Thomae $\mathrm{GmbH}$, Biberach, Germany) in the perfusate was determined at 30-minute intervals.

\section{Experimental protocol}

The lung preparations were randomly assigned to the different groups. To study alterations of pulmonary vascular permeability after incorporation and metabolisation of the different lipid emulsion, either $2.5 \mathrm{ml}$ Lipovenös ${ }^{\circledR} 10 \%(\mathrm{n}=11)$ or $2.5 \mathrm{ml} \mathrm{Omegavenös}{ }^{\circledR} 10 \%(\mathrm{n}=13)$ corresponding to $70 \mathrm{mg}$ $\mathrm{lipid} / \mathrm{kg}$ body weight, were added to the perfusion fluid. Lungs in which $2.5 \mathrm{ml}$ saline was injected into the perfusate served as controls $(n=3)$. In order to investigate selectively lipid metabolisation via the lipoxygenase pathway, the cyclooxygenase-blocker diclofenac $(10 \mu \mathrm{g} / \mathrm{ml})$ was applied. Dimetidenmaleate and cimetidine were injected into the perfusion fluid to exclude unspecified histamine-reactions which might interfere with leukotriene-induced reactions on vascular permeability. After a 30-minute isogravimetric steady-state period, the first perfusate sample was drawn for measurements of baseline values. The baseline capillary filtration coefficient $\left(\mathrm{C}_{\mathrm{fc}}\right)$ was determined by venous pressure elevation of $7.5 \mathrm{mmHg}$. After the first $\mathrm{C}_{\mathrm{fc}}$ measurement, all lungs except controls were stimulated with A23187 yielding in a final concentration of $1 \mu \mathrm{mol} / \mathrm{l}$. The used dosage of calcium-ionophore A23187 was selected to investigate acute effects due to unspecified inflammatory stimulation on pulmonary vascular resistance and permeability and mediator release. In preliminary dose-response studies $(n=8)$, this amount was shown to induce inflammatory reactions such as significant histamine release and eicosanoid generation, a marked activation of granulocytes with elastase release, and a moderate increase in pulmonary vascular resistance and microvascular permeability. Higher doses resulted in overwhelming pressure increases followed by immediate alveolar flooding and severe barotrauma of the lung, whereas lower doses produced an insufficient mediator release hardly detectable in the perfusate by the used methods.

During and after the following 210-minute lipid perfusion period, $\mathrm{C}_{\mathrm{fc}}$ was measured at 30-minute intervals. In order to study lipid effects on neutrophil-mediated inflammatory reactions, the same protocol was performed in additional experiments in which isolated washed human PMN-leukocytes $\left(156 \pm 13 \times 10^{6}\right)$ were added to the perfusion fluid prior to injection of Lipovenös ${ }^{\circledR} 10 \%(n=4)$ and Omegavenös ${ }^{\circledR} 10 \%$ $(n=4)$, respectively. Leukotriene generation was analysed in these experiments before, as well as 60,120 and 180 minutes after A23187-stimulation. The elastase inhibitor Eglin (r(Ac)Eglin, Ciba Geigy, Basel, Switzerland) was added to the perfusate prior to ionophore challenge. This served to inhibit protease-induced effects on vascular permeability which might mask effects due to the different mediator profile in the Lipovenös ${ }^{\circledR}$ - and Omegavenös $\AA$-perfused lungs.

In additional pilot experiments, it was tested whether perfusion with either Lipovenös ${ }^{\circledR}(n=6)$ or Omegavenös ${ }^{\circledR}$ $(n=6)$ per se led to vascular reactions and mediator release in our model. Since increasing doses from $1 \mathrm{ml}$ up to $10 \mathrm{ml}$ of each lipid emulsion per $250 \mathrm{ml}$ perfusate induced neither alterations in vascular tone and permeability nor mediator generation, the observed effects after calcium-ionophore stimulation could be mainly attributed to the different spectrum of metabolites.

\section{Gravimetric estimation of capillary filtration coefficients $\left(C_{f c}\right)$}

$\mathrm{C}_{\mathrm{fc}}$ expresses the proportionality between net fluid filtration and the balance of hydrostatic and oncotic forces across the microvascular membrane. The technique of gravimetrically determining $\mathrm{C}_{\mathrm{fc}}$ used in the present study was developed by Drake, Smith and Gabel in intact dog lungs. ${ }^{23} \mathrm{C}_{\mathrm{fc}}$ was determined from the slope of lung weight change per time after venous pressure elevation up to $7.5 \mathrm{mmHg}$. The hydrostatic challenge was maintained over a period of 7 minutes for each $\mathrm{C}_{\mathrm{fc}_{\mathrm{c}}}$ estimation. Previous experiments showed that this procedure of venous pressure elevation did not enhance the subsequent weight gain. Both the ventilation and flow (at $200 \mathrm{ml} / \mathrm{min}$ ) were maintained during hydrostatic challenge. The tangent to the slope of the slow phase of weight gain was taken, beginning at 2 minutes until 7 minutes after onset of the pressure rise. The rapid weight gain during the first 2 minutes and the corresponding weight loss after the hydrostatic challenge was considered a vascular filling effect. ${ }^{24}$ $\mathrm{C}_{\mathrm{fc}}$ was obtained as the slope of the tangent relating the average weight change per time induced by pressure elevation related to the calculated pulmonary capillary pressure (PCP) (expressed in $\mathrm{ml} \cdot \mathrm{min}^{-1} \cdot \mathrm{mmHg}^{-1} .100 \mathrm{~g}$ wet weight ${ }^{-1}$ ) in each group. The capillary pressure was estimated according to Drake et al: ${ }^{25}$

$$
\mathrm{PCP}=\mathrm{PVP}+0.44(\mathrm{PAP}-\mathrm{PVP})
$$

The filtrate was assumed to have unitary density. The wet lung weight was calculated from the body weight (BW) of the animal using $\mathrm{BW}(\mathrm{g}) \times 0.0024$. In preliminary experiments this factor had been determined as the ratio between the wet weight of the lung, corrected for the vascular volume by previous application of ${ }^{125} \mathrm{I}$-albumin, and the $\mathrm{BW}$ of the rabbits (standard race and breed set). ${ }^{26}$ This had turned out to be a more precise method than draining the vascular compartment, weighing the lungs at the end of the experiment, and thereby subtracting the measured overall weight gain. During pressure elevation up to $7.5 \mathrm{mmHg}$ to determine $\mathrm{C}_{\mathrm{fc}}$, the bulk of the lungs were under zone III conditions (peak inflation pressure 3.5-5.0 $\mathrm{mmHg}$ ), thus major influence of changes in surface area on $\mathrm{C}_{\mathrm{fc}}$ estimations were improbable.

\section{Preparation of PMN-leukocytes}

Granulocytes were prepared according to a method of Hjorth ${ }^{27}$ using Percoll@.

\section{Analysis of leukotriene generation}

Reversed phase high pressure liquid chromatography (HPLC) was used for separation and quantification of tetraen- and pentaen-leukotrienes. Released leukotrienes were extracted from a $10 \mathrm{ml}$ aliquot of lung perfusion fluid each time by 
octadecyl solid phase extraction columns (SEP-PAK $\mathrm{C}_{18}$ cartridges, Waters Associates, Milford, USA), as described. ${ }^{28}$ Conversion into methyl esters was performed by addition of freshly prepared diazomethane in diethyl ether. Leukotrienes were then eluted with $1 \mathrm{ml}$ methanol and the solvent was evaporated. The residues were taken up in $0.05 \mathrm{ml}$ of methanol and chromatographed isocratically, using reversed phase HPLC on a Octadecylsilyl column (particle size: $5 \mu \mathrm{m}$ [Hypersil, Fa. Marchery-Nagel, Düren, Germany], mobile phase: methanol/water/acetic acid, 72.9:27.3:0.16, pH 4.9). Leukotrienes were conventionally detected at $270 \mathrm{~nm}$ (Spectroflow 773 Absorbance detector, Kratos analytical instruments, Karlsruhe, Germany). All obtained data are given in $\mathrm{pmol} / \mathrm{ml}$ of perfusion fluid. The retention times of the LT were compared with the retention times of authentic LTstandards (Fa. Paesel, Frankfurt/M, Germany).

\section{Materials}

A cell- and plasma-free perfusion medium was used in the present study in order to avoid the complex interactions with different circulating cells which may mask direct effects on vascular tone and mediator release. The perfusate consisted of a Krebs-Henseleit buffer solution with additional human albumin (Rhodalbumin ${ }^{\circledR}$ 20\%, Merieux GmbH, Leimen, Germany) in order to maintain a colloid oncotic pressure between $23-25 \mathrm{mmHg}$, yielding in final concentrations of: albumin $20 \mathrm{~g} / \mathrm{l} ; \mathrm{Na}^{+} 138 \mathrm{mmol} / \mathrm{l} ; \mathrm{K}^{+} 4.5 \mathrm{mmol} / \mathrm{l} ; \mathrm{Mg}^{2+} 1.33$ $\mathrm{mmol} / \mathrm{l} ; \mathrm{Cl}^{-} 135 \mathrm{mmol} / \mathrm{l}$; $\mathrm{Ca}^{2+} 2.38 \mathrm{mmol} / \mathrm{l}$; glucose $12 \mathrm{mmol} / \mathrm{l}$; $\mathrm{HCO}_{3}^{-} 12 \mathrm{mmol} / \mathrm{l}$. The osmolality was approximately $330 \mathrm{mOsm} / \mathrm{kg}$ (Mikro-Osmometer, Roebling Meßtechnik, Berlin, Germany). The $\mathrm{pH}$ of the buffer solutions was adjusted to 7.4 with $0.1 \mathrm{M} \mathrm{NaHCO}_{3}$ just before cannulation. Effects due to endotoxin contamination of the plasma-free perfusate can be excluded in our model as assessed by previous experiments. Calcium-ionophore A23187 was purchased from Sigma Chemical (Munich, Germany).

The lipid emulsions Omegavenös ${ }^{\circledR} 10 \%$ prepared from fish oil and Lipovenös ${ }^{\circledR} 10 \%$ produced from soy oil were a generous gift from Dr E Schlotzer, Fresenius AG (Bad Homburg, Germany). Both are $10 \%$ fatty acid emulsions. The used batches of Omegavenös $\AA 10 \%$, rich in long chain $n-3$ fatty acids, yielded in final concentrations in the emulsion: eicosapentaenoic acid (C20:5n3) $19 \mathrm{mg} / \mathrm{ml}$, docosahexaenoic acid (C22:6n3) $25 \mathrm{mg} / \mathrm{ml}$, palmitic acid (C16:0) $12 \mathrm{mg} / \mathrm{ml}$, stearic acid (C18:0) $2.5 \mathrm{mg} / \mathrm{ml}$, oleic acid (C18:1n9) $14 \mathrm{mg} / \mathrm{ml}$, linoleic acid (C18:2n6) $2.7 \mathrm{mg} / \mathrm{ml}$, linolenic acid (C18:3n3) $0.7 \mathrm{mg} / \mathrm{ml}$, arachidonic acid (C20:4n6) $2.2 \mathrm{mg} / \mathrm{ml}$, other fatty acids $27.3 \mathrm{mg} / \mathrm{ml}$. The major components of Lipovenös ${ }^{\circledR}$ $10 \%$, rich in n-6 fatty acids were: linoleic acid $51 \mathrm{mg} / \mathrm{ml}$, linolenic acid $7.2 \mathrm{mg} / \mathrm{ml}$, oleic acid $22.4 \mathrm{mg} / \mathrm{ml}$, palmitic acid $12 \mathrm{mg} / \mathrm{ml}$, stearic acid $4 \mathrm{mg} / \mathrm{ml}$ and other fatty acids $10 \mathrm{mg} / \mathrm{ml}$.

\section{Statistical analysis}

Data are presented as means \pm standard error of the mean (SE). Differences between groups were tested by one-way analysis of variance (ANOVA) followed by Scheffé's multiple comparison procedure. Significance was accepted at $\mathrm{p}<0.05$.

This study was approved by the Animal Subject Protection Committee of the University of Giessen. The care and handling of animals were in accordance with the principles expressed in the Helsinki Declaration.

\section{Results}

After an isogravimetric equilibration period either saline, Lipovenös ${ }^{\circledR}$ or Omegavenös ${ }^{\circledR}$ was added to the perfusate. Baseline values of PAP between 7.5 and $8.5 \mathrm{mmHg}$, and airway pressure between 4 and $5.5 \mathrm{mmHg}$, were similar in all groups and in agreement with our own previous studies..$^{29,30}$ The initial capillary filtration coefficient $\left(\mathrm{C}_{\mathrm{fc}}(0)\right)$ achieved a mean value of $0.23 \pm 0.1$ g. $\mathrm{min}^{-1} . \mathrm{mmHg}^{-1} .100 \mathrm{~g}^{-1}$ in all groups. Concentrations of leukotrienes were not detectable $(<0.5$ $\mathrm{ng} / \mathrm{ml}$ ). The lungs were challenged with calcium-ionophore A23187 $(1 \mu \mathrm{M})$ in order to study the metabolism of n-3 fatty acids in states of an enhanced AA turnover due to inflammatory stimulation.

\section{Changes in capillary filtration coefficient}

Calcium-ionophore stimulation caused a gradual increase of $\mathrm{C}_{\mathrm{fc}}$ in all experimental groups and was most pronounced in the Lipovenös ${ }^{\circledR}$-perfused lungs. For comparison of groups the alterations in $\mathrm{C}_{\mathrm{fc}}$ were expressed as quotients, relating the $\mathrm{C}_{\mathrm{fc}}$ at the various time points to the baseline value $\mathrm{C}_{\mathrm{fc}}(0)$ (Figure 1). In the Lipovenös ${ }^{\circledR}$-treated lungs, there was more than a 24-fold $\mathrm{C}_{\mathrm{fc}}$ increase until the end of observation (210 minutes post-A23187 injection), whereas the maximum increase in the Omegavenös ${ }^{\circledR}$ group reached only a mean value of 15.9 . During Lipovenös ${ }^{\circledR}$ perfusion the increase in $\mathrm{C}_{\mathrm{fc}}$ was significantly higher $(\mathrm{p}<0.05)$ at $60,90,180$ and 210 minutes

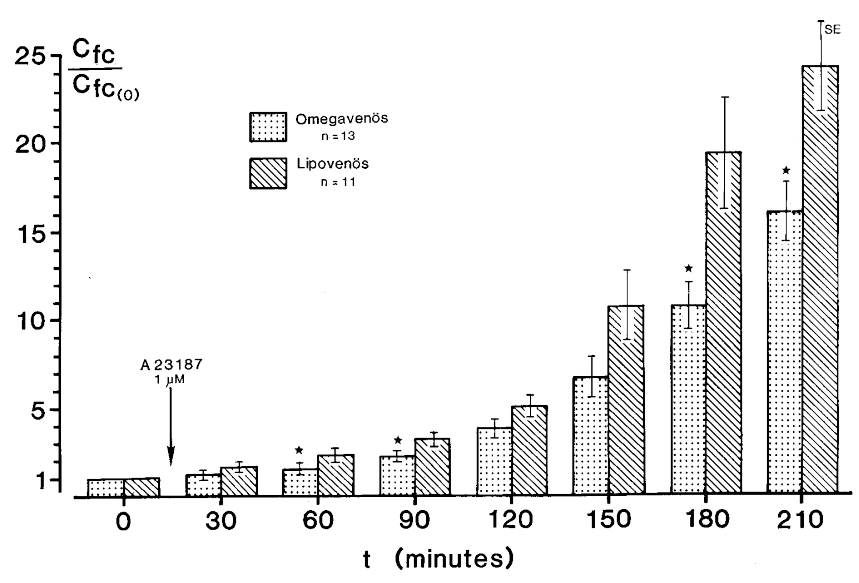

Figure 1 Increase in capillary filtration due to calcium ionophore $(1 \mu \mathrm{M})$ challenge in cell-free perfused lungs, expressed as a quotient of $\mathrm{Cfc}$ at the various time-points related to the baseline value $\mathrm{Cfc}(0) . \mathrm{Cfc} / \mathrm{Cfc}(0)$ was significantly reduced $(\mathbf{p}<0.05)$ in the Omegavenös ${ }^{\circledR}$ group at 60,90 , 180 and 210 minutes. Data given are mean $\pm S E$. * $\mathbf{p}<0.05$ versus corresponding values in Lipovenös ${ }^{\circledR}$ group. 
after ionophore-challenge compared with the Omegavenös ${ }^{\circledR}$ treated lungs.

To investigate the effect of n-6 and n-3 fatty acids in the presence of PMN-leukocytes, which are known to be the main source of leukotriene production, the same protocol was applied in further experiments after addition of PMN to the perfusate and subsequent calcium-ionophore challenge. In comparison with the cell-free perfused lungs similar results were obtained in the presence of PMN-leukocytes, thus showing a significantly blunted increase $(\mathrm{p}<0.05)$ of pulmonary vascular permeability quantified as $\mathrm{C}_{\mathrm{fc}}$ in the Omegavenös ${ }^{\circledR}$-treated lungs at $90,120,150$, and 180 minutes after application of A23187 (Figure 2). Perfusion with the n-3 fatty acid emulsion resulted in a reduced increase in capillary filtration, as evidenced by $30 \%$ lower filtration coefficients, compared to the corresponding values in the lungs treated with the n-6 lipid emulsion. In the presence of neutrophils A23187 injection evoked a more rapid increase in $\mathrm{C}_{\mathrm{fc}}$ than in the cell-free perfused lungs, accompanied by an enhanced weight gain. The maximum increase in capillary filtration $\left(\mathrm{C}_{\mathrm{fc}} / \mathrm{C}_{\mathrm{fc}}(0)\right)$ of approximately 24 in the Lipovenös ${ }^{\circledR}$ and of 15 in the Omegavenös ${ }^{\circledR}$-treated lungs, respectively, was already reached at 180 minutes after A23187 injection. All lungs challenged with calcium-ionophore in the presence of PMN developed severe lung oedema before the end of the observation period (210 minutes post-A23187 injection).

In the lipid-free perfused unstimulated controls only minor changes in $\mathrm{C}_{\mathrm{fc}}$ occurred during the whole observation period, thus implying that repetitive hydrostatic challenges $(7.5 \mathrm{mmHg}$ ) for estimation of the filtration coefficient did not severely impair lung barrier function.

The oncotic pressure and the $\mathrm{pH}$ measurements showed no significant changes during the experiments in either group.

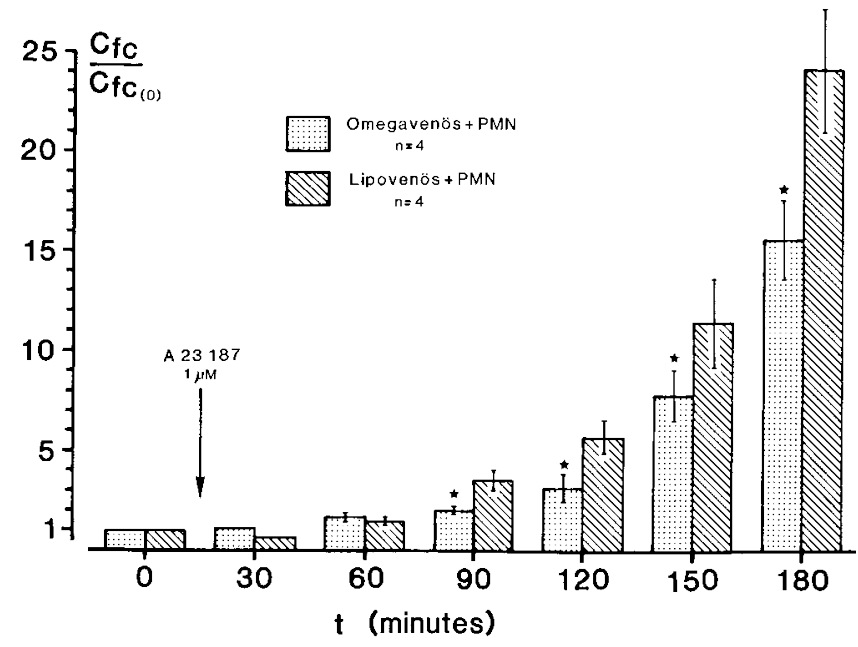

Figure 2 Increase in capillary filtration $\left(\mathrm{C}_{\mathrm{fc}} / \mathrm{C}_{\mathrm{fc}}(0)\right)$ due to calcium ionophore $(1 \mu \mathrm{M})$ challenge in the presence of PMN-leukocytes $\left(156 \pm 13 \times 10^{6}\right)$ perfused with either Lipovenös ${ }^{\circledR} 10 \%(n=4)$ or Omegavenös ${ }^{\circledR} 10 \%(n=4)$. Data given are mean \pm SE. * $\mathbf{p}<0.05$ versus corresponding values in Lipovenös ${ }^{\circledR}$ group.

\section{Mediator profile}

The reported alterations in $\mathrm{C}_{\mathrm{fc}}$ were paralleled by a different profile of leukotriene generation in the PMN-perfused lungs. To determine the mediator spectrum reflecting the metabolism of the applied fatty acids, perfusate samples were analysed during lipid perfusion at hourly intervals. Since AA and EPA are precursors of metabolites which differ in one double bond, lipoxygenase products were differentiated in the AAderived tetraene- and the EPA-derived pentaene-leukotrienes. The exemplary measurements of leukotrienes by HPLC methods demonstrated that EPA-derived $\mathrm{LTB}_{5}, \mathrm{LTC}_{5}$ and LTE $_{5}$ appear very early (after 1 hour) in the perfusate of the Omegavenös ${ }^{\circledR}$-perfused lungs, thus implying that $n-3$ fatty acids had been metabolised after short-term infusion. LTD $_{5}$ could only be measured in insignificant quantities. In contrast to the Omegavenös ${ }^{\circledR}$-treated lungs, no detectable amounts of pentaene leukotrienes were found during Lipovenös ${ }^{\circledR}$ perfusion. Figure 3 demonstrates the pattern of 5-series leukotrienes $\left(\mathrm{LTB}_{5}, \mathrm{LTC}_{5}\right.$ and $\left.\mathrm{LTE}_{5}\right)$ found in the Omegavenös ${ }^{\circledR}$ treated lungs. The rapid rise in 5-series LTs in the Omegavenös ${ }^{\circledR}$ group with EPA:AA product ratios surpassing $10-30 \%$ was paralleled by a substantial decrease in 4 -series leukotrienes (Figure 4). The total amount of tetraene-LTs was reduced to less than $40 \%$ of LT-concentrations obtained in the Lipovenös ${ }^{\circledR}$-perfused lungs. The most convincing suppression of mediator generation was detectable in $\mathrm{LTE}_{4}$ concentrations (Figure 4d). Lipovenös ${ }^{\circledR}$ perfusion resulted in mean $\mathrm{LTE}_{4}$

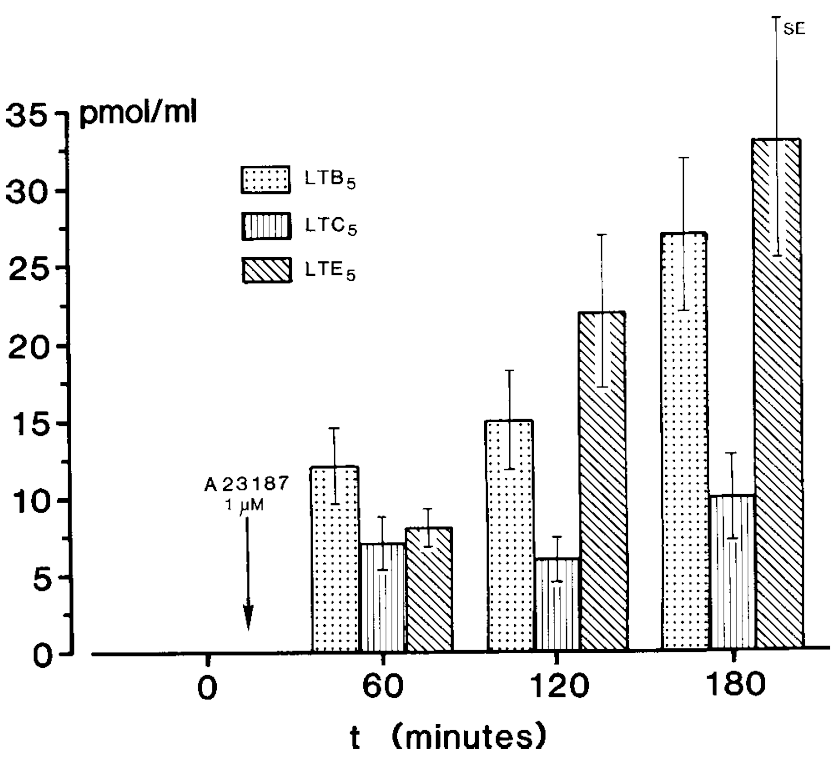

Figure 3 EPA-derived 5-lipoxygenase product formation ( $\left.\mathrm{LTB}_{5}, \mathrm{LTC}_{5}, \mathrm{LTE}_{5}\right)$ upon calciumionophore stimulation, measured (HPLC) in the perfusion fluid of lungs perfused with Omegavenös ${ }^{\circledR} 10 \%(n=4)$. In contrast to the Lipovenös ${ }^{\circledR}$-treated lungs in which no 5-series leukotrienes were detectable, $\mathrm{LTB}_{5}, \mathrm{LTC}_{5}$, LTE $_{5}$ appeared after 1 hour in the perfusate in the Omegavenös ${ }^{\circledR}$ group. Data given are mean \pm SE. 

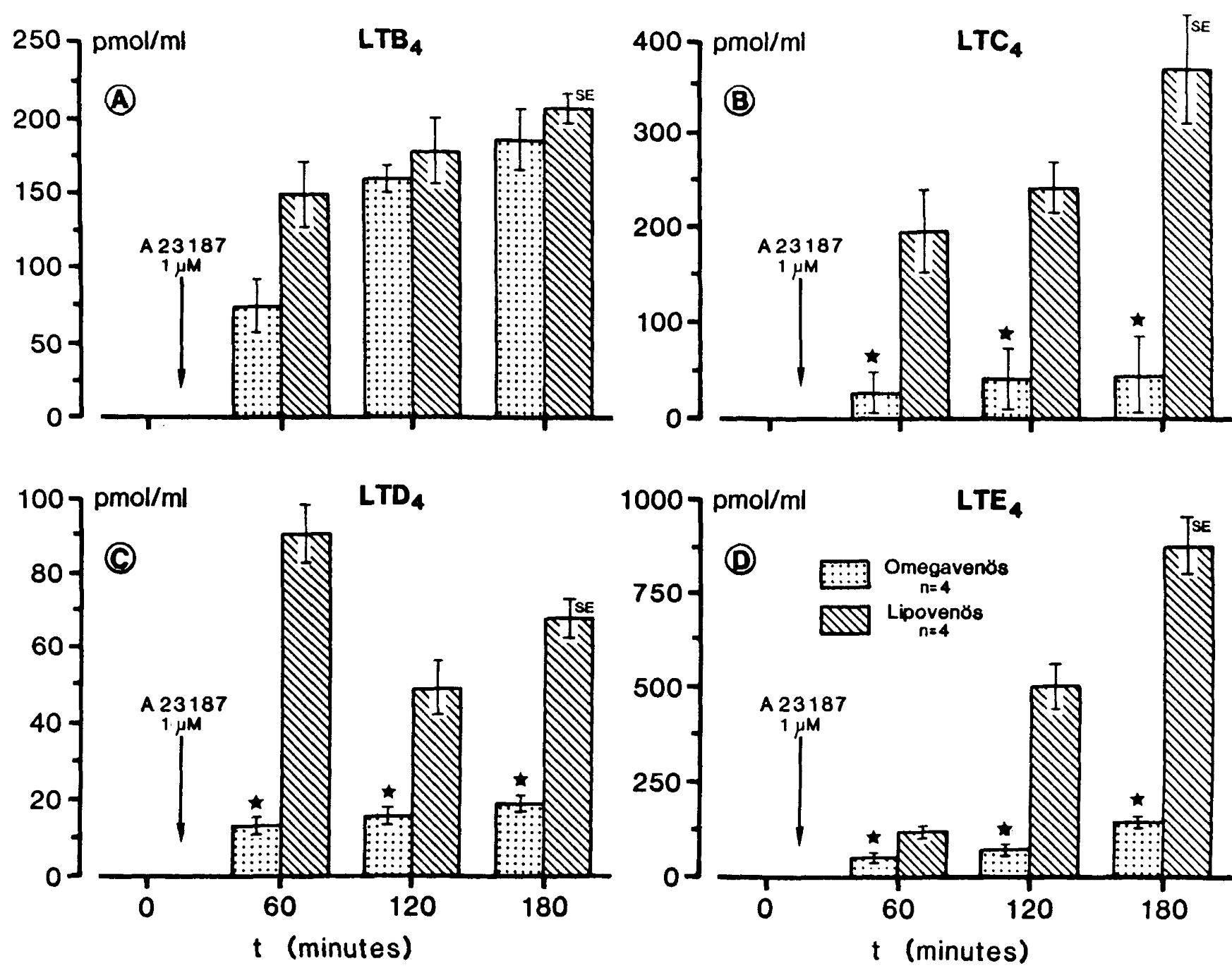

Figure 4 a) to d) Comparison of AA-derived 5-lipoxygenase product formation upon calcium-ionophore stimulation in the lungs perfused with either Lipovenös ${ }^{\circledR} 10 \%(n=4) \mathbb{W}$ or Omegavenös ${ }^{\circledR} 10 \%(n=4)$ 同. Tetraeneleukotrienes were substantially reduced in the Omegavenös ${ }^{\circledR}$ group compared with Lipovenös ${ }^{\circledR}-$ perfused lungs. Data given are mean $\pm \mathrm{SE}$.

production of $876 \mathrm{pmol} / \mathrm{ml}$, while the corresponding value in the Omegavenös ${ }^{\circledR}$-perfused lungs reached only mean values of $152 \mathrm{pmol} / \mathrm{ml}$. Equally, $\mathrm{LTC}_{4}$ release was reduced to $13 \%$ of mean concentrations (42 pmol/ml versus $324 \mathrm{pmol} / \mathrm{ml}$ ) detected under Lipovenös ${ }^{\circledR}$ perfusion (Figure $4 b$ ). Similarly, Leukotriene $\mathrm{B}_{4}$ generation was moderately suppressed after application of Omegavenös ${ }^{\circledR}$ solution (Figure 4a). Consequently, the application of Omegavenös ${ }^{\circledR}$ leads to a markedly reduced production of tetraene-LTs and a rapid rise in the less permeability enhancing pentaene-LTs due to calcium-ionophore challenge. These effects were associated with a significantly attenuated increase in capillary filtration.

Exemplary radioimmunological measurements of histamine release into the perfusate revealed no detectable amounts in either Lipovenös ${ }^{\circledR}$ - or Omegavenös ${ }^{\circledR}$-perfused lungs.

\section{Discussion}

Arachidonic acid metabolites have long been implicated in the pathogenesis of pulmonary oedema following trauma, shock and sepsis. ${ }^{21}$ In particular, the 5-lipoxygenase products $\mathrm{LTB}_{4}, \mathrm{LTC}_{4}$ and $\mathrm{LTE}_{4}$ and hydroxyeicosatetraenoic acids have been shown to impair lung barrier function in numerous experimental studies investigating ARDS. ${ }^{31,32}$ Further evidence of the involvement of AA lipoxygenase products in the development of ARDS is obtained from the beneficial effects of administered lipoxygenase inhibitors in animal models. ${ }^{33}$

Recently, dietary enrichment of PMN phospholipid pools with n-3 fatty acids has attracted attention as a putative therapeutic regimen for mitigating PMN- and eicosanoidrelated inflammatory events. ${ }^{34,35}$ Neutrophils, isolated after intake of an n-3 fatty acid-supplemented diet, exhibited a several fold increase in EPA-derived 5-lipoxygenase products associated with a moderately reduced generation of AAderived leukotrienes upon in vitro ionophore challenge. A variety of responses to inflammatory stimuli, including chemotaxis, were noted to be diminished in these PMN. ${ }^{36}$ LTB-5 generated in EPA-enriched PMN possesses more than 
a 10 -fold reduced chemotactic and PMN activating capacity compared to $\mathrm{LTB}_{4},{ }^{37}$ resulting in a net anti-inflammatory effect of $\mathrm{LTB}_{5}$.

Based on this reasoning, this study was designed to investigate whether short-term infusion (3 hours) of n-3 fatty acids was able to influence the development of pulmonary oedema due to acute inflammatory stimulation, and thus might be of therapeutic interest in the treatment of critically ill patients. For this purpose, the effect of a fish oil-derived lipid emulsion on vascular permeability and mediator release was tested compared with a soy oil emulsion in a reproducible animal model. We monitored both impairment of lung barrier function in terms of the capillary filtration coefficient and lipid mediator profiles in response to n-3 versus n-6 lipid supplementation. In view of the clinical use of these lipid emulsions, the parenteral application was tested to overcome slow kinetics and limited availability of dietary fatty acid supplementation for modulation of inflammatory mediator spectrum. The synthetic calcium-ionophore A23187 was used in the present study as it is representative of a great variety of exogenous and endogenous stimuli characteristically found in sepsis and trauma which induce the synthesis of arachidonic acid metabolites. A23187 increases intracellular $\mathrm{Ca}^{2+}$ levels by opening calcium channels in the cell membrane analogous to the effects of pore-forming bacterial toxins (for example, Staphylococcal a-toxin, E coli hemolysin, Pseudomonas aeruginosa cytotoxin). ${ }^{38,39}$

The generation of eicosanoids, caused by a broad spectrum of different stimuli, seems to be a common pathophysiological mechanism leading to increased vascular tone and disturbances of epithelial and endothelial barrier function in the microcirculation of the lung and other organs. Since this pathophysiological concept seems to be of significance in various species, including humans, experimental studies on animal models may contribute to elucidate the complex interactions involved in the pathogenesis of ARDS and multiple organ failure. In particular, it could be demonstrated that the pattern of the generated eicosanoids in the pulmonary circulation and their vascular reaction is comparable in rabbits and human beings. ${ }^{40,41}$

Summarising the current data, there is evidence that the EPA-enriched fish oil emulsion Omegavenös ${ }^{\circledR}$ exerts a protective effect on pulmonary vascular permeability due to inflammatory stimulation. This was indicated by significantly reduced capillary filtration and a decrease in leukotriene production in the Omegavenös ${ }^{\circledR}$-perfused lungs compared with those lungs treated with Lipovenös $\AA$. Since calciumionophore injured lungs with no lipids added to the perfusate showed a significantly higher increase in pulmonary arterial pressure and oedema formation compared to Omegavenös ${ }^{\circledR}$ treated lungs in our previous study, ${ }^{20}$ a protective effect of $n-3$ fatty acids on inflammatory vascular reaction can be assumed. In the present study, the vascular reaction in terms of alterations of $\mathrm{C}_{\mathrm{fc}}$ was investigated in the absence and presence of PMN. Both experimental designs gave qualitatively identical data, but oedema formation was more enhanced when leukocytes were added to the perfusate. This might be explained by an increased mediator release into the perfusate since leukocytes are potent leukotriene-producing cells. LT measurements in cell-free perfused lungs which revealed quantities below the detection limits of the used method supported this assumption. For this reason the leukotriene spectrum was analysed in the perfusion fluid of PMN perfused lungs. We found a markedly reduced synthesis of AA-derived 4-series LTs and a moderate increase in EPA-derived 5-series lipoxygenase products in the Omegavenös ${ }^{\circledR}$-perfused lungs. These results are in accordance with previous findings investigating leukotriene production of isolated neutrophils after intake of n-3 fatty acids. ${ }^{35,36}$ In contrast to the Omegavenös ${ }^{\circledR}$-perfused lungs, no detectable concentrations of 5-series leukotrienes were found in the Lipovenös ${ }^{\circledR}$-treated lungs, whereas the total amount of tetraen LTs reached considerably higher values. Blunted oedema formation may be related to the synthesis of biologically less active EPA-derived 5-lipoxygenase products and to the inhibition of the inflammatory functions mediated by 4 -series leukotrienes, respectively.

Since effects on vascular permeability due to histamine release, which was not detectable in either group, or due to the lipid emulsion itself seem unlikely, the reduced oedema formation in the lungs pretreated with Omegavenös ${ }^{\circledR}$ could be attributed to the less harmful biological properties of the EPA-derived leukotrienes.

When analysing the biochemical and physiological results in our model, it has to be taken into account that Omegavenös ${ }^{\circledR}$ contains not only EPA but also AA, as well as its precursors, in considerable amounts which may partially mask the effects of EPA on pulmonary vascular permeability and mediator generation.

Besides the described beneficial effects on pulmonary capillary filtration in our model, the effects of n-3 fatty acids on leukocyte endothelial cell interactions have been evaluated in in vitro and in vivo studies. ${ }^{42,43}$ It has been suggested that dietary fish oil prevents leukocyte/endothelium interaction through the inhibition of leukotriene biosynthesis of series 4 . Evidence is provided that $\mathrm{LTB}_{4}$ induces leukocyte adhesion to the endothelium through upregulation of CD11b/CD18 adherence receptors on the leukocyte surface. ${ }^{44} \mathrm{EPA}$-derived $\mathrm{LTB}_{5}$, however, is less potent in upregulating CD11b/CD18 by two orders of magnitude. ${ }^{37}$ EPA attenuates leukocyte/ endothelium interactions not only by inhibition of adhesionpromoting mediators but also by enhanced generation of antiadhesive forces, particularly by increased prostacyclin formation. In addition, EPA derived cyclooxygenase products have generally been shown to exert less vasoconstrictive and thrombotic effects than the corresponding 2-series prostanoids, and may therefore contribute to the overall anti-inflammatory potency of n-3 fatty acids.

Although this study investigates only a part of the broad spectrum of biological effects induced by EPA under defined experimental conditions, the results suggest that n-3 fatty acids, apart from the nutritional aspect, may be a useful therapeutic approach in critically ill patients. In view of the current data, it can be concluded that the infusion of EPAenriched lipid emulsion is capable of reducing pulmonary vascular permeability, presumably due to an altered mediator profile of 5-lipoxygenase products. Supplementation of n-3 fatty acids induces a variety of further metabolic changes, including the inhibition of oxygen radical generation and the 
release of PAF and cytokines ${ }^{18,46}$ which have all been implicated in the inflammatory response. Hence, lipid emulsions based on fish oil may exert protective effects on the pulmonary vasculature and, possibly, on multiple organ failure development. From the clinical point of view, these findings imply that the use of EPA-enriched lipid emulsions may thus combine parenteral nutrition and an anti-inflammatory intervention in critically ill patients.

The present study suggests that the use of n-3 fatty acids seems to be a promising therapeutic approach for the amelioration of acute inflammatory processes. The causal relationship between the improvement in clinical manifestations and measured changes in eicosanoid generation remains to be elucidated in future studies.

\section{Acknowledgements}

The authors thank A Weber and H Michnacs for excellent technical assistance, P Müller for skilful graphic illustration and $\mathrm{T}$ Wieth for proofreading this manuscript.

\section{References}

1. Dyerberg J, Bang HO, Hjorne N. Fatty acid composition of the plasma lipids in Greenland eskimos. Am J Clin Nutr 1975; 28: 958-66.

2. Dyerberg J, Bang HO. Haemostatic function and platelet polyunsaturated fatty acids in Eskimos. Lancet 1979; ii: 433-5.

3. Kromhout D, Boschieter EB, del Coulander C. The inverse relation between fish consumption and 20-year mortality from coronary heart disease. N Engl J Med 1985; 3: 1205-9.

4. Dolecek TA, Grandits G. Dietary polyunsaturated fatty acids and mortality in the Multiple Risk Factor Intervention Trial (MRFIT). In: Simopoulos AP, Kifer RR, Martin RE, Barlow SM (Eds). Health Effect of Omega-3 Polyunsaturated Fatty Acids in Seafoods. World Review of Nutrition and Dietetics, vol 66. Munich, Karger Verlag, 1991, 205-16.

5. Aslan A, Triadafilopoulos G. Fish oil fatty acid supplementation in active ulcerative colitis: A double-blind, placebo-controlled, crossover study. Gastroenterology 1992; 87: 432-7.

6. Bittiner SB, Tucker WF, Cartwight I, Bleehan SS. A doubleblind, randomised, placebo-controlled trial of fish oil in psoriasis. Lancet 1988; i: 378-80.

7. Kojima T, Terano T, Tanabe E, Okamoto S, Tamura Y, Yoshida S. Long-term administration of highly purified eicosapentaenoic acid provides improvement of psoriasis. Dermatologica 1991; 182: $225-30$.

8. Simopoulos AP. Omega-3 fatty acids in health and disease and in growth and development. Am J Clin Nutr 1991; 54: 438-68.

9. von Schacky C, Fischer S, Weber PC. Long-term effects of dietary marine omega-3 fatty acids upon plasma and cellular lipids, platelet function, and eiocsanoid formation in humans. J Clin Invest 1985; 76: 1626-31.

10. Weber PC. Clinical studies on the effect of n-3 fatty acids on cells and eicosanoids in cardiovascular system. $J$ Intern Med 1989; 225: 61-8.

11. Brown AJ, Pang E, Roberts DCK. Persistent changes in the fatty acid composition of erythrocyte membranes after moderate intake of n-3 polyunsaturated fatty acids: study design implications. Am J Clin Nutr 1991; 54: 668-73.

12. Chilton FH, Patel M, Fonteh AN, Hubbard WC, Triggiani M.
Dietary n-3 fatty acid effects on neutrophil lipid composition and mediator production. Influence of duration and dosage. $J$ Clin Invest 1993; 91: 115-22.

13. Urakaze M, Hamazaki T, Makuta M et al. Infusion of fish oil emulsion: effects on platelet aggregation and fatty acid composition in phospholipids of plasma, platelets, and red blood cell membranes in rabbits. Am J Clin Nutr 1987; 46: 936-40.

14. Croset M, Bayon Y, Lagarde M. Incorporation and turnover of eicosapentaenoic and docosahexaenoic acids in human blood platelets in vitro. Biochem $J$ 1992; 281: 309-16.

15. Bourre JM, Bonneil M, Dumont $\mathrm{O}$ et al. Effect of increasing amounts of dietary fish oil on brain and liver fatty acid composition. Biochim Biophys Acta 1990; 1043: 149-52.

16. Fischer $\mathrm{S}$, Weber PC. Prostaglandin $\mathrm{I}_{3}$ is formed in vivo in man after dietary eicosapentaenoic acid. Nature 1984; 307: 165-8.

17. Strasser T, Fischer S, Weber PC. Leukotriene $B_{5}$ is formed in human neutrophils after dietary eicosapentaenoic acid. Proc Natl Acad Sci USA 1985; 82: 1540-3.

18. Sperling RI, Robin J-L, Kylander KA, Lee TH, Lewis RA, Austen KF. The effects of n-3 polyunsaturated fatty acids on the generation of platelet-activating factor-acether by human monocytes. J Immunol 1987; 139: 4186-91.

19. Fischer S. Dietary polyunsaturated fatty acids and eicosanoid formation in humans. Adv Lipid Res 1989; 23: 169-98.

20. Koch T, Duncker HP, Klein A et al. Modulation of pulmonary vascular resistance and edema formation by short-term infusion of a 10\% fish oil emulsion. Infusionther Transfusionsmed 1993; 20: 291-300.

21. Neuhof H. Actions and interactions of mediator systems and mediators in the pathogenesis of ARDS and multiorgan failure. Acta Anaesthesiol Scand 1991; 35: 7-14.

22. Seeger W, Walmrath D, Menger M, Neuhof H. Increased lung vascular permeability after arachidonic acid and hydrostatic challenge. J Appl Physiol 1986; 61: 1781-9.

23. Drake RE, Smith JH, Gabel JL. Estimation of the filtration coefficient in intact dog lungs. Am $J$ Physiol 1980; 238: H430-8.

24. Richardson PDJ, Granger DN, Taylor AE. Capillary filtration coefficient: the technique and its application to the small intestine. Cardiovasc Res 1979; 13: 547-61.

25. Drake R, Gaar KA, Taylor AE. Estimation of the filtration coefficient of pulmonary exchange vessels. Am J Physiol 1978; 234: H266-74.

26. Chang RSY, Wright K, Effros RM. Role of albumin in prevention of edema in perfused rabbit lungs. J Appl Physiol 1981; 50: 1065-70.

27. Hjorth R, Jonson A-K, Vretbald P. A rapid method of purification of human granulocytes using Percoll. A comparison with dextran sedimentation. J Immunol Methods 1981; 43; 95-101.

28. Schulz R, Seeger W. Release of leucotrienes into the perfusate of calciumionophore stimulated rabbit lungs. Influence of 5lipoxygenase-inhibitors. Biochem Pharmacol 1986; 35: 183-93.

29. Koch T, Duncker HP, Rosenkranz S, Neuhof H, van Ackern K. Alterations of filtration coefficients in pulmonary edema of different pathogenesis. J Appl Physiol 1992; 73: 2396-402.

30. Koch T, Duncker HP, Heller A, Schaible R, Neuhof H, van Ackern K. Effects of stroma free hemoglobine solutions on pulmonary vascular resistance and mediator release, in the isolated perfused rabbit lung. Shock 1994; 1: 146-52.

31. Hua XY, Daglen SE, Lundberg JM, Hammarström S, Hedqvist P. Leukotrienes $\mathrm{C}_{4}, \mathrm{D}_{4}$, and $\mathrm{E}_{4}$ cause widespread and extensive 
plasma extravasation in the guinea pig. Arch Pharm (Weinheim) 1985; 330: 136-41.

32. Noonan T, Kern DF, Malik AB. Pulmonary microcirculatory response to leukotrienes $\mathrm{B}_{4}, \mathrm{C}_{4}$ and $\mathrm{D}_{4}$ in sheep. Prostaglandins 1985; 30: 419-34.

33. Seeger W, Menger M, Walmrath D, Becker G, Grimminger F, Neuhof H. Arachidonic acid lipoxygenase pathways and increased vascular permeability in isolated rabbit lungs. $\mathrm{Am}$ Rev Respir Dis 1987; 136: 964-72.

34. Grimminger F, Mayser $\mathrm{P}$, Papavassilis $\mathrm{C}$ et al. A double blind, randomized, placebo-controlled trial of n-3 fatty acid based lipid infusion in acute, extended guttate psoriasis. JClin Invest 1993; 71: 634-43.

35. Grimminger F, Führer D, Papavassilis $\mathrm{C}$ et al. Influence of intravenous n-3 lipid supplementation on fatty acid profiles and lipid mediator generation in a patient with severe ulcerative colitis. Eur J Clin Invest 1993; 23: 706-15.

36. Lee TH, Hoover RL, Williams JD et al. Effect of dietary enrichment with eicosapentaenoic acids on in vitro neutrophil and monocyte leukotriene generation and neutrophil function. N Engl J Med 1985; 312: 1217-24.

37. Lee TH, Sehti T, Crea AE et al. Characterization of leukotriene $\mathrm{B}_{3}$ : comparison of its biological activities with leukotriene $\mathrm{B}_{4}$ and leukotriene $\mathrm{B}_{5}$ in complement receptor enhancement, lysozyme release and chemotaxis of human neutrophils. Clin Sci (Colch) 1988; 74: 467-75.

38. Seeger W, Bauer M. Bhakdi S. Staphylococcal a-toxin elicits hypertension in isolated rabbit lungs. Evidence for thromboxane formation and the role of extracellular calcium. J Clin Invest 1984; 74: 549-58.
39. Suttorp N, Seeger W, Uhl J, Lutz F, Roka L. Pseudomonas aeruginosa cytotoxin stimulates prostacyclin production in cultured pulmonary artery endothelial cells: membrane attack and calcium influx. J Cell Physiol 1985; 123: 64-72.

40. Ball HA, Cook JA, Wise WC, Halushka PV. Role of thromboxane, prostaglandins and leukotrienes in endotoxic and septic shock. Intensive Care Med 1986; 12: 116-26.

41. Antonelli M, Bufi M, De Blasi RA et al. Detection of leukotriene $\mathrm{B}_{4}, \mathrm{C}_{4}$ and their isomers in arterial, mixed venous blood and bronchoalveolar lavage fluid from ARDS patients. Intensive Care Med 1989; 15: 296-301.

42. Lehr H-A, Hübner C, Finckh B et al. Dietary fish oil reduces leukocyte/endothelium interaction following systemic administration of oxidatively modified low density lipoprotein. Circulation 1991; 84: 1725-31.

43. Payan DG, Wong MYS, Chernov-Rogan T et al. Alterations in human leukocyte function induced by ingestion of eicosapentaenoic acid. J Clin Immunol 1986; 6: 402-10.

44. Lindström P, Lerner R, Palmblad J, Patarroyo M. Rapid adhesive responses of endothelial cells and of neutrophils induced by leukotriene B4 are mediated by leucocytic adhesion protein CD18. Scand J Immunol 1990; 31: 737-44.

45. DeCaterina R, Giannessi D, Mazzone A et al. Vascular prostacyclin is increased in patients ingesting omega-3 polyunsaturated fatty acids before coronary artery bypass graft surgery. Circulation 1990; 82: 428-38.

46. Endres S, Ghorbani R, Kelley VE et al. The effect of dietary supplementation with $n-3$ polyunsaturated fatty acids on the synthesis of interleukin-1 and tumor necrosis factor by mononuclear cells. N Engl J Med 1989; 320: 265-71. 